\title{
8 Entertainment (and Edification)
}

It is the little rift within the lute,

That by and by will make the music mute

Alfred, Lord Tennyson

Before American power encircled the globe with its far-flung military tentacles, a preplanned post-World-War Two phenomenon, it had already swept the world, several times over, with its cinema, its music, its flapdoodle, its merry bcreed of consumption, its philosophy of optimism, and its celebration of the moment, the immmediate now, the herepresent. In terms of defining a unique cultural attribute, it would have to be this amazing propensity in America to ignore both the past and the future; to think neither backwards nor forwards, but to immerse themselves, and occupy themselves, thoroughly, with today. As coarse American wit will have it, if I have one leg in the past and one leg in the future, then there is only one thing I can do to the present. Memory is the heirloom of reactionaries, heathens, pagans, who are not yet ready to worship the here-and-now god of consumption, without mind and soul, but with all our sensual bodies; history can only hold you back, leash your wild impulses, still your natural restlessness - we don't have time for it. And the future is an unknown, we ain't seen it, and we never will; so why worry?

Combine these attitudes, and we get the familiar picture of not learning from our mistakes, of being obliged to reinvent the wheel, again and again, and living in the radically compressed short run; the short run is a business metaphor, of course, but it is also a metaphor for life. In the long run we are all dead, said Keynes, the English economist, echoing a modernist Anglo-Saxon sentiment: the short run is all we have. And living in the short run does have its upside; life is a gas, and we try to keep the fun times rolling, as long as we can. The down side is we don't see what's coming, until it's too late, like the Japanese, for instance, with their small cars in the sixties; our car-makers looked to short run profits, as given by the sancrosanct quarterly figures, and things looked good: why change from big cars to small cars, gas guzzlers to fuel economy? - hey, if it's working, don't fix it! And then, by the time we woke up, the folks who had given us Pearl Harbor (itself, and this is little known, a response to leaked US plans to attack Japan) got really serious with their Toyotas, Nissans, and Hondas. Today, Detroit is street-smart with their cars, but at the cost of over $20-25 \%$ per cent of the domestic car market (of course, today the City is virtually extinct).

It's just the way we are, we can't help it; it's youthfulness and spirits abounding, and the world (which has its head screwed on the wrong way, anyway) loves us for it; it's what makes us attractive, despite our nastiness. Youthfulness is something that neither the Old world, nor the orient, could ever hope to devolve to; but, we have it, like we invented it. The cheerfulness of everyday America ( fake and real) is almost too much to take for one bred in the solemn silences, the grim, baneful, contemplativeness, of an older, sadder, civilization. I come from India where noise cacopho- 
nous does abound on the street, unfailing symptom of creeping urban modernity, but where thinking people generally seek silence and solitude, away from the mob, to reflect upon mortality, suffering, and the hereafter.

It's all rather dreary, doleful, and depressing; life is a wretched illusion, misery its sure accompaniment, and pain and suffering the ultimate, unavoidable, certainties. It's not the kind of psyche that dreams up roller-mania, videogames, or skydiving - the best minds don't (yet) work for IBM, but hang out in the mountains (or academe) instead, seeking solitude, seclusion, and retreat. To dwell, unremittingly, on the unhappiness of life is a sort of a popular, perhaps even ancient, Indian pastime (though I understand that now, there too, color tv, iPods, and the internet are making daring inroads into peace and quiet). Expose the serenity of such a yogi to the nonstop, high-pitched, neurotic, perfervid, excitement of American radio and tv and his nervous system collapses readily, unused to such feverish, and suitably lowly, stimulation. The higher self is revolted, and withdraws peevishly, and in bad humor; the lower self takes its jacket off, rolls up its sleeves, and starts to have a ball. The struggle between the two selves becomes a sort of an epic drama, a saga of unpredictable wins and losses.

At any rate, the noise, the hype, the hoop-la of America, philosophically, is the antidote to all intimations of mortality; it is this stance that separates it decisively from the older civilizations. It is almost as if the captains of commerce, on to their marbles, decided to saturate the economy with things-to-do, to the accompaniment of heavy metal, turning the system into a giant Disneyland, where a thrill, and a throb, however cheap and artificial, are ever round the corner, ever just a step ahead, so we are all turned into expectant children, ready always for the next gasp of disbelief, the next gee-whiz, the next omigod, as the great amusement park of life unfolds.

Most Europeans think of Americans as children who never grow up; and they are right: it is not our mental age that is set permanently at five, though, as unkind European critics have it (even if newspapers are written with 6th grade proficiency in mind), but our emotional age, that stays pretty close to infantile throughout. This is quite significant, for any appreciation of American culture; the American is a child in two fundamental respects: the child has no concept of mortality, hence the unhampered, insouciant play, - and the child has no intimation of either the past, or the future on its mind, living, always, in the magic of the undying present.

The child is fickle, passing from amusement to amusement, toy to toy, tiring easily; the child needs continuous coddling, comfort, reassurance; the child has a limited attention span, is thoughtlessly cruel, and emotionally variable. The child disclaims responsibility: 'I didn't do it'; or, 'it's not my fault'; think of it: is there anyone you know who still accepts accountability - for we are now a nation of buck-passers even as a notion? Anyone who does not recognize these as all-American traits has never been to America.

In some forty years of living in America, I must have discussed almost every subject on earth with my American friends; but the issue of death has never come 
up. Death is a bummer, of course, and, by repute, a great kill-joy; therefore, it is never to be brought to the fore of consciousness. The subject, like the dead themselves, is banished from the horseplay of everyday life, veiled in a dark shroud; dying, though expensive, is not a creditable capitalist activity - you'd be considered a very bad sport, I imagine, if you suddenly dropped dead, say, in the middle of a movie, or a cocktail party; only a dweeb, or a dork, would do a thing like that.

Dying is best reserved, out of sight, for a sanatorium, or an old-age home, out of city limits, to be done with quietly, privately, and without fuss. I am reminded, in contrast, of the way the dead are carried in India, borne by pall bearers, and walked through town, accompanied by loud, ceremonious chanting, a stern, social reminder of what's in store for all of us, causing the sinners to tremble, the covetous to check themselves, the wicked to say a prayer, and everyone to file the day away in filled with dark reflections upon our mortal lot. An impatient, business civilization instinctively recoils at that, knowing that only living immortals may be avid buyers and sellers, zealous producers and consumers.

If the suppression of Eros is necessary to get people to work, the denial of Thanatos is also necessary to help us immerse ourselves in current joys, careless of thoughts of tomorrow (and tomorrow never comes, remember!). So I am giddy with myself, high on the unchained spirits, into the non-stop party life is promised to be. Not having either beginning or end, I am free to invent myself anew (nobody cares to stop and notice me; they're all busy doing the same thing), every day - if I so choose; vegetarian today, Hare Krishna tomorrow, neo-fascist the next day, and so on. I am 'into' this, I am into that; I will never be the same two months running; every fad and fancy will have me attracted, sold, and immersed - for a while; and then I move on, looking for the next set of kicks. Of course, we'll call it all 'personal development', to make it sound rather high-minded and progressive, speaking well of our openness to new things - and new things, mind, is precisely what the system turns out endlessly, recurrently, continuously.

Capitalism would be dead and gone if people weren't ready to try on every new gizmo, every new technology, every new gimmick, the market churned up, every time it did, again and again, in ever larger numbers; indeed, no system is more revolutionary - at least in its product lines. None of this would be at all possible if people had any degree of fixity in their views, in their philosophy, in their convictions; no, we've gotta be open, plural, receptive, every day of the year (if your mind is too open, your brains fall out; but that's another matter). No one needs to be centered, no one wants to be, no one is expected to be; the market will bend us, shape us, any way it wants to, and we, the passive seekers of delight will adjust our lives, our life-styles, as needed.

The market breaks up the family without remorse; first, the three generational one, next the two generational one, and now the one-generational one. The atomization is relentless; one integrated family, buys only one tv set; fifteen, atomized, kinless, individuals, rack in fifteen - be it tv sets, cars, washers and all. The market logic is impeccable, and it triumphs totally; we all adjust our notions of the family appropri- 
ately, aided by a helpful media portraying these economic necessities as desirable. Society, meaning the establishment, plays with us as with silly putty, and we still continue to flaunt our 'individualism', thinking all things brave and beautiful originate with us, deep within our own sovereign selves. Remember the times when it wasn't ok to sell your mother? Of course you don't! Now, you can sell her on Ebay.

The daily hypnotic trance we slip into is quite impregnable; within that psychedelic bell-jar, we leave the created world, and live in our own, programmed cubicles, moving about like well-oiled modules of latent desire; stirring only when prompted, noticing only that much of the world that is of advantage and benefit, screening out all else that may clamor for attention. As a teacher, I try desperately to get my students to snap out of that swoon, to penetrate that armor, to reach the spirit within, trying trick, stratagem, and ruse, but it little avails; I might as well ask a tortoise to jump out of its shell, the stupor is so thick, the catalepsy so deep.

Indeed they are part offended at my exertions; I am breaking the rules, violating their privacy, intruding into their space. Of course, they will respond when the time is right, as coded by regulation and rule - to select buzz-words that percolate in, and bodily needs that emanate out. And, after a season or two of trying, I give up and get a death mask of my own; now I, too, can flit about efficiently, revelling in my own preoccupations, careless of others - the distance demanded of me now being in place. We are now, the ideal tutor and pupil; all is calm, all is well.

The British author of White Hotel came to the U.S. on a lecturing assignment, took one look at his class, and went straight back home never to return; he was not ready to bare his artistry to a bunch of stolid philistines (reminiscent of Swami Vivekananda, Indian mystic and guru in the 1890's, in a talk on Christianity, in Boston, was so repulsed by his audience, that he broke into a rage, saying: '...with all your brag and boasting, where has your Christianity succeeded without the sword? Yours is a religion preached in the name of luxury. It's all hypocrisy that I have heard in this country. All this prosperity, all this from Christ! Those who call upon Christ care nothing but to amass riches! Christ would not find a stone on which to lay his head among you...you are not Christians, Return to Christ !')

The elixir of youth is available to all, with glitzy packaging, and we are all nearly drunk on it, a society of rabid consumers, each on a different fix, starry eyed, and trance-like, going through the day in a dream, the week in a daze, a life in a reverie. To whet our already turgid appetites, to pump up the adrenalin, to boost our red corpuscle count, there must be a non-stop, insensible, mindless, background, drone instrument capable of sustaining a permanent high; our need for compulsory, endless entertainment stems from such roots. Of course, the entertainment asked for, and provided, is purely passive; it must not interfere, must not demand, must not challenge, criticize, ask, or importune.

Muzak does it, the ipod will do it, the nine thousand magazines you can buy at the newsstand do it, radio does it, tv does it, Hollywood does it, the drugstore novel does it (even the news, sensationalist mélange as it is, is a form of week-day amuse- 
ment, turning off for most of the week-end - as if the world stopped spinning - to make way for other diversions); best of all, real, hallucinatory, drugs do it. Books can be read backwards, movies can be walked into at any time, tv can run all day, chattering to itself excitedly, decibels higher than the dull human conversation around it. Entertainment is the accompaniment to our consumptive lives, the silencer of the Silence that gnaws at us, and no society provides more by way of such fare than America with its ever gamboling technology - exploring new frontiers of art without representation, music without genre, cinema without voice. There must be something doing, all the time; indeed only two things, I submit, will bring this country to violent revolution: zapping tv transmissions altogether, and closing supermarkets - for just one week-end.

It's as if the moment we stop doing, we die; we are flung into that dingy hell of schism, self-doubt, fear, and anxiety that must be avoided at all costs. We must never stop, never step out of line, never tread outside ourselves, to review matters; to stop is to lose it all very quickly, to fall apart, to go to pieces. I remember being struck by this quality of restiveness in the American temperament, observing it in my friends visiting India in the bad old sixties, when so many took to the trails of the big yonder to dodge the draft. So long as motion was continuous, all was well - the moment there was a slack in social, or physical, life they got decentered, nervous and fractious.

I remember it particularly because not to do anything at all (dolce far niente!), with the stillness of the universe inside me, was my own favorite pastime; by contrast, my American pals were always on the go, it seemed: eating, chewing gum, smoking, reading papers, listening to music, arguing, fighting, dancing, drinking, buying, selling, bantering, and, god knows what. They were working hard, it seemed, even at play; back then, I took it as a manifestation of a general Calvinism that would not let them relax at anything - now I know it's a lot more complex than that, a uniquely American thing. The only time they were able to unwind, was at drink or drugs; indeed, only marijuana and hashish seemed to really undo the tightly-wound machinery, the deeply instilled robotics, by killing those ever-running alkaline batteries for a while: it seemed a pity to me then - it seems so now, as well. They had lost the capacity for reverie, that makes us all comprehending parts of this unbounded, enigmatic, universe.

There has been much talk, amongst intellectuals, of the de-industrialization of America, of the end of the old smokestack industries, of the eclipse of the old bluecollar worker; we are supposed to be in a post-industrial age, heading for a service economy, processing information, selling software, and marketing lifestyles. Within that new utopia, the entertainment industry will have a secure place; CNN plays all over the world, MTV just as much, and Hollywood, almost perished in the sixties, is back on high with artificial life-supports, the world over. Our films may not be the best, but they are the biggest (in impact), and the most widely distributed; our music may not be the best, but it's the biggest such industry there is, the biggest market; America entertains itself, and the world, through its multiple media, by microwave, 
cable, and satellite. Cruise, Pitt, and DiCaprio, are household words from Jordan to Jamaica; Katy Perry, the rage from Bremen to Bombay; Steven King and Spielberg, as well known as any local celebrities from Rio to Rangoon; Batman and Superman as popular as Coke and Pepsi.

There's a near-riot in Bombay when an American film closes without warning; a protest in Germany when Michael Jackson pulled out of a scheduled appearance; a panic in New Delhi when they can't tune in to CNN. The world is ours, don't you know, hooked on our tunes, our celluloid, our metallic tapes, our compact disks. The sheer heteronomy of our entertainment is unbeatable, unmatched; in just one category, film alone, the choices are dizzy: at the corner videomart, I can get porn (soft, hard, or vicious), violence, drama, thrillers, comedy, history, war, classics, martial arts, family, children's and more; there's something for everyone, a fix for every kick, a bait for every hook, no matter how trivial, how illicit, the need, the urge, the itch.

And they buy it, by the million, everywhere; Stephen King sells in the land of Shakespeare and Shaw, in the nation of Tolstoy and Chekhov, in the homeland of Goethe and Schiller; Madonna sells in even more countries. The age of high culture and criticism, even amongst the pretentious, is over; the ultimate irony, to me, was to see portly Englishmen in London, in impeccable Harris Tweed, wait in the autumn rain, half a mile from the entrance, in a line that wound around entire city blocks, waiting patiently (but without much aplomb) for the opening of the newest McDonald's; what poetic justice! The bigoted high country snobs of England, for generations contemptuous of things American, finally bending down, pants off, and taking six of the juiciest - from the lowliest plastic food corporation of America! The world we have conquered without the Marines is much larger, and more securely ours, than the one reaped by arms; we cater, unabashedly, to the lowest common denominator in Culture and, naturally, have our efforts been colossally well-rewarded. The average Hollywood film (which is now aped by Bollywood) is made up of female body-parts and guns, in the main, loosely strung together with foul language, unspeakable depictions of people, and slick, fast-paced, locales, sound bites, and editing; you don't need to be a film-critic to ponder the basics of its knee-jerk appeal, the world over. Good taste, everywhere, shrinks instinctively from the ephemera of American artefacts; but good taste, everywhere, is less widespread than the other kind - and so America succeeds where others would be hard-pressed even to compete. Bad taste, to coin a phrase, drives good taste out of circulation.

Year after year, our standards decline and our critical threshold is lowered; degrading language, debasing situations, deemable an $\mathrm{R}$ rating a few years ago would qualify as PG now, and so on, in steady, relentless, regression - another form of the all-pervasive desublimation I mentioned earlier, and just as repressive. Records speak to savage violence, cds to racism, and tapes to sadistic sexism - and it all sells, barring the odd, voice-in-the-wilderness protest, here and there, that seems to get nowhere. Everyone is into exploitation; Hollywood, the music business, the entertainment business; and we are powerless to stop the rot, to stem the decay, hung by 
our own commercial prejudices, hoisted by our own negative, unreflecting, regressive, concepts of 'freedom'.

Eighteenth-century England is usually held to be barbaric in its tolerance of bearbaiting, cock-fighting, fox-hunts, and the like; but where do we stand in that calculus of culture? Hollywood reproduces Life, and life, even more readily, reproduces Hollywood, true to formula; 'great knockers, babe', sings out an eight year old, on a skateboard, to a woman of thirty-five entering a supermarket, with children; eleven year olds are in juvenile court for rape of nine-year olds, with fiendish instruments; twelve year olds are in for murder. And the insensate system lives on, not caring, unruffled, Unmoved; we are not our brother's keeper - standards, civic, moral, ethical, are nobody's business.

The ideology of the system sanctions rabid relativism; hard headed materialists laugh at morality as a conservative notion devoid of content, fit only for old women, the weak, the impotent, the reactionary. The bourgeois have no morals, wrote Marx, except that of deriding all morality; precisely - and yet, what a hideous perversion it all is! Society, first and foremost, is a moral community, before it can be any other. When the social cement decays, so does our moral sense, our sense of belonging, our sense of identity, our sense of being, and we are truly reduced to that bitter Hobbesian world of 'a war of each against all', with neither rationale, meaning, nor purpose. We have an innate sense of freedom, says Noam Chomsky, linguist, philosopher and radical intellectual, that expresses itself in our social lives; if so, the other twin attribute of freedom must be a moral sense, for freedom as a value, is quite inconceivable without a moral philosophy.

It is almost passe to suggest that capitalism degrades culture, commodifies it, debases it; that much we have all known, for over a century now, from seeing the devolution of culture in European society from the nineteenth-century on (though, it's gone so far, nobody complains anymore : there's nobody left to remember); but that it can actually destroy all culture - except a corporatist parody of it - in its wake, we are only realizing in the America poised now to take over, unilaterally, the twentyfirst century, en masse. Henry Miller had portentous things to say about cultural decay in this country as early as 1945, even before the big post-war reconstruction of American life had actually commenced:

'...it was like a bad dream. But we look at these bad dreams constantly with eyes open.... and we go about our business or we take to dope, the dope which is worse by far than opium or hashish - I mean the newspapers, the radio, the movies. Real dope gives you the freedom to dream your own dreams; the American kind forces you to swallow the perverted dreams of men whose only ambition is to hold their jobs together regardless of what they are bidden to do. The most terrible thing about America is that there is no escape from the treadmill which we have created. There isn't one fearless champion of truth in the publishing world, not one film company devoted to art instead of profits. We have no theatre worth the name, and what we have of theatre is practically concentrated in one city; we have no music worth talking about except what the Negro has 
given us, and scarcely a handful of writers who might be called creative. We have murals decorating our public buildings which are about on par with the aesthetic development of high school students, and sometimes below that level in conception and execution. We have art museums that are crammed with lifeless junk for the most part. We have war memorials in our public squares that must make the dead in whose name they were erected squirm in their graves. We have an architectural taste which is about as near the vanishing point as it is possible to achieve.'

Think of it: this was written before chrome and glass; before the likes of Nixon, Haldeman, and Ehrlichman, yesteryear; before the vcr, dvd, and broadband; before the video-arcade, Ronald Reagan, and Donald Trump, before George Bush and Donald Rumsfeld, before the Sears Tower, the Bonaventura Hotel, and Ted Bundy. How much teflon can the system stand? Philosophers speak, passively, of the arrival of mass culture; of the Waning of Affectivity, of the Fragmentation of the Subject, of the emergent cultural style of blank, humorless, parody; of the drift to anonymity, of the Dissolution of Significance - all amounting to that vacuum called post-modernism, our new dominant ethos, inward oriented, autistic, and auto-referential. We have nothing left to say, since everything has been said (John Cage, the avant garde genius of the 'new classical' music said it for many: 'I have nothing to say and I am saying it'); and no one to say it to, because no one is listening - and so we all pass each other, like ships in the night, not knowing where we are bound to: it is the ultimate fantasy of a fully privatized, desocialized, idiocy.

I can get no satisfaction, stomped the Stones way back in 1965 (in the 'modernist' period of rock), validating the frustration of the 'protest' generation, a lot of angry young men and women just come of age; today, we are so sure of it, we don't even bother looking for it - and we're neither angry, nor all that young any more (the same Stones, mellowed, would later sing, 'You can't always get what you want', in self-conscious irony), either in spirit or in flesh. Rock rose with the Sixties, and fell, quite co-opted, in the seventies, in a decade long slide of the primal Woodstock nation (entombed finally with Lennon, december of 1980), to be briefly revived by Punk (the Sex Pistols, etc.), born in New York and England, in the seventies, but dead in the U.S., soon thereafter.

An thought cerebral protest-idiom had devolved into theme muzak (soft rock, country rock, art rock, glitter rock, and so on); into a hundred fragments, each with its own non-descript cult status, tribal insignia, and following. Where are the American bands now with something to say (the troubled stylists of the sixties genre, Hendrix, Joplin, Morrison, killed themselves quite early in the game), other than a smattering of black rap artists (inspired by reggae, and Jamaican styles) speaking to and from the ghetto? The last echoes of old rock idioms, hearkening to the probing/questioning defiance of the sixties, or at least reminiscent of them, in both form and content, came from abroad: Peter Gabriel, U2, Bob Marley (although the lyrics of the British band Cure's 'Friday, I'm in love', early nineties number one in the U.S. charts, in opposite fashion, defined where we're at, socio-politically, in this respect, quite succinctly). 
Today, the eclectic jumble of pop/hip-hop/dance-pop, in cheerful bubble-gum drivel, caps that swell of vacuity by ensuring sweet nothings at the cost of compete inanity. The closing of the American mind? Really!

Film, of the critical kind, was always a European genre, too, be it from East or West; who are our great directors infusing cinema with bold, new, content (with Superman and Batman staging a comeback, and Green Lantern awaiting its turn)? How many of us know of, let alone have seen, Barton Fink? Where is our great literature that rises above kitsch (Mailer and Vidal, last of a line, are already history), and Love Story level of tripe?; where is the theatre that goes beyond the soft-core, gelatinous, plastic of Broadway? All are fallen to bottom-line thinking, to bottom-line calculations, to bottom-line reckonings.

I could not even begin to describe the incredible blandness of the nightly Sitcom, a representative idiom of tv fare; a market must be sold to, this market must be as wide as possible, it should not tread on any toes (at least explicitly), it should help shore up what passes for 'family values' (as guessed at by the scriptwriters, naturally; but this didactic function is quite important;), and should provide some obvious, well-worn, low-brow, usually cheesy, humor. Marketing is assisted by a little - but not a lot - controversy, tossed in at midstream to rouse up any waning of influence; I am reminded of the now hoary Murphy Brown series, as the last Century faded, and the big fuss over the 'unwed mother' motif (assisted, then, by an obligingly moralizing vice-president). The fact that unwed mothers can provoke agitated controversy (was the Press really that bored to death?), then on the brink of the twenty-first century, only indicated, ostensibly, how far behind the rest of the world the American mainstream was and still is; mind you, it is important to realize that most of the huffing and puffing was pure simulation, hypocrisy, and make-believe.

The game goes like this; tv first puts on a scam suggesting that the American mainstream, here and now, shares the values of the frontier family (a la the Little House on the Prairie) of 1646 (another popular ideological fiction, but that's another matter); the real American mainstream, pure polyglot, all flattered, joins in the gag and pretends stoutly to those 'values' in public discourse. Then tv throws in an 'unwed mother' in prime time, and we can all throw a fit and bring the heavens down: what a fake-out ! In real life, we deal with child rape, incest, teen-age mothers and bisexuality, without half the excitement, and perturbation, we show at Murphy Brown. There's the heritage of Shaw and Ibsen, looking only to liberal feminism, almost a century old; then there's Murphy Brown, as social comment, in the nineties. As for the trite fare of Friends and Seinfeld, they are in the genre of pure ersatz: shows, in desperate search of a point. I can get no satisfaction, wailed the Stones, still in an age of innocence; what is satisfaction?, ask their epigones, today, in all bewilderment.

It's over: and we should know it; we're stuck with tv, videos, movies, the internet, as our dominant entertainment media - we don't need to go out and meet them (that would be too social an activity): they beam themselves into our homes, and, at the turn of a dial, at the push of a button, become our friends, our daily visitors, our sur- 
rogate family. These insensate gorgings of the senses have no need for respite; we can skip from medium to medium, at will, for all the good it does us, from sex, to tv, to stuffing our faces; eating, like sex, being just another form of entertainment. I go to a show, any kind, comic, serious, whatever, and the viewers march back and forth, carrying troughs full of popcorn, pails full of coke, and great big sacks of candy; and, all through the show, the munching, the chewing, the drinking, the tearing of wrappers, does not stop; they come in eating, they go out eating.

Some day we shall not even have to stir; great, big, intravenous devices will pump Coke and Pepsi and Pizza straight into our veins; electrodes, attached to our brains will stimulate the images of several full-length movies we can watch with our eyes closed, over and over, as we lie in our beds fiddling absently with a little remote monitor controlling the portable entertainment center, and the blow-up rubber doll that will simulate our sexual fantasies; then, may be we'll be 'satisfied,' finally, in our all-industrial utopia, in this beast of all possible worlds. When good Americans die, they go to Paris, wrote Oscar Wilde, in a different time, a different age; now they live in, not just go to, Disneyworld.

In the same way that our culture is dead, or dying, so are the empty calories, of chemically stabilized foods, we ingest in obscene quantities - a quarter of a billion people in this world go hungry, every day; a hundred million of them children, under the age of five; and we go on stuffing ourselves to the point of disease, eating disorders, and death (spending ten times more on remedial treatment for overeating, than is spent on hunger-relief expenditures in the erstwhile 'third-world'. But let's forget the 'third world', whipping boy for all our misanthropic fancies: thirty-five million right here in this country go hungry, while the rest of us gorge ourselves sick).

And what of the dry, desiccated, insipid, food we gulp down two, three, times a day? Hypermedicated, chemically poisoned, hormone injected, artificially bred (in that chilling, cold-blooded, catatonic cruelty that profit-making rationality invariably enjoins), animal flesh, bursting with fat, cholesterols, and assorted carcinogens; frozen, packaged, foods with about as much nutrition on the inside as in the wrapping; high-sugar treats enabling even juveniles to turn diabetic; junk food, that lives up to its name two hundred per cent; fast food that perishes, nutritionally, even faster than you can eat it; fruits sprayed with dioxins; vegetables, genetically engineered.

Agro-Business has been out readying our lunch for years now, with GMOs and animals injected with hormones, replacing the complexity, the diversity, the richness of natural food chains (30 per cent of the world's wheat comes now from just one parent stem; 70 per cent of corn from but six parent plants, and so on) with hybrid, sterile, drugged, cloned, genetically modified, zombies that can be patented, mass produced, and marketed the world over, totally indifferent to either flavor (I remember tasting real vegetables again, in all rapture, after 15 years of eating sterile supermarket swill in America, when I returned to India - where they still haven't caught up, despite trying hard, with our state of food processing), food value, or the security of our fragile ecosystem, vulnerable, in the extreme, to disturbances in the food web. 
For food raised dead, frozen to death, and nuked back to life, the all-American restaurant diner is the appropriate mortuary, the fitting resting place; or try a tv dinner at home - what a choice, felicitous, coupling of terms, incidentally! - that will do to your insides what the ordinary tv show does to your brain.

And yet, what incredible possibilities exist in this effulgent world of worlds!; what a mix of human types and talents from all corners of the globe - what incredible contributions to a living culture could have been made possible if the laws of profit-taking had not crushed creativity, choked independence, and killed off the freefloating imagination? The tragedy of America is not just what it has produced, phoenix like, out of the ashes of its European origins, but what it has destroyed; not the nightmarish boorishness that is our proud, national character now, but the possibility of civilization that it has rendered positively dysfunctional, out of order, and obsolete; not the gruffly material paradise of inanity, vacuousness, and illiteracy, that it has generated, but the severe liability it has placed on all grace, temperance, and virtue, not just here, and for us, but for the world at large, for everyone (but let us hope, not for evermore).

Compare the New York subway, circa the seventies, a grimy tunnel of urban grunge, to the Moscow Metro, then or now, a marble palace lit with classical music, and you get the feel for what we are, for what we tolerate, for what we acquiesce to, what we accept as all right; and yet we have won, by thunder, and they have lost. The Soviet Union was a magnificent dream of social amelioration that turned into a squalid, sullen, vapid, nightmare of grim, arid materiality - while our own inspirations have never been loftier than the old stand-bys of gluttony, carnality, and avarice. They are punished by failure; but, far worse, we are gibbetted by success. 